\title{
The anterior approach for the treatment of posterior osteochondral lesions of the talus: comparison of different surgical techniques
}

Peter Cornelius Kreuz • Matthias Steinwachs •

Max Edlich · Timm Kaiser · Jörg Mika •

Andreas Lahm $\cdot$ Norbert Südkamp

Published online: 12 September 2006

(C) Springer-Verlag 2006

Erratum to: Arch Orthop Trauma Surg 126:241-246

DOI 10.1007/s00402-005-0058-5

Owing to an unfortunate error, the first name of one of the authors was mistakenly given. Tim Kaiser should be Timm Kaiser.

The online version of the original article can be found at http://dx.doi.org/10.1007/s00402-005-0058-5.

P. C. Kreuz $(\varangle) \cdot$ M. Steinwachs $\cdot$ M. Edlich $\cdot$ T. Kaiser

J. Mika · A. Lahm · N. Südkamp

Department of Orthopaedic and Trauma Surgery,

Albert Ludwig University of Freiburg,

Hugstetter Str. 55, 79106 Freiburg, Germany

e-mail: peter.kreuz@uniklinik-freiburg.de 